\title{
Photosynthetic rates of four tree species in the upper canopy of a tropical rain forest at the Pasoh Forest Reserve in Peninsular Malaysia
}

\begin{abstract}
Measurements of photosynthesis (A) and stomatal conductance (gs) were conducted using the leaves of four tropical tree species (Dipterocarpus sublamellatus, Neobalanocarpus heimii, Ptychopyxis caput-medusae, and Xanthophyllum amoneum) in the canopy of the lowland forest at the Pasoh Forest Reserve in peninsular Malaysia. A canopy walkway was used to reach the canopy of 30- to 40-m-tall trees and diurnal changes in A and gs were determined. The diurnal patterns for A differed between days and between species, though A of the four species were similar but quite low. In general, A increased with increasing photosynthetically active radiation (PAR) before noon, then declined. As well, a linear relationship was detected between gs and A, but no statistically significant correlation could be confirmed between these two factors for D. sublamellatus and P. caput-medusae in November and July. The value of gs decreased with increasing vapor pressure deficit for D. sublamellatus, but the other species did not show this response.
\end{abstract}

Keyword: Canopy; Diurnal changes; Tropical forest; Photosynthesis; Stomatal conductance 